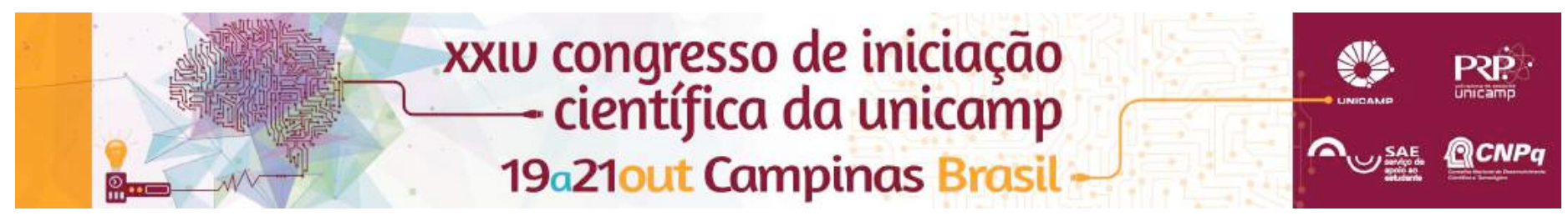

\title{
AVALIAÇÃO DO PROCESSO INFLAMATÓRIO INDUZIDO PELO CONTATO PREMATURO UNILATERAL POSTERIOR NA ARTICULAÇÃO TEMPOROMANDIBULAR DE RATOS
}

\author{
Caio A Hashizume*, Henrique Abdalla, Ricardo Bonfante, Nádia C Fávaro-Moreira, Cristina M Maganin, \\ Frederico Andrade e Silva e Juliana T Clemente Napimoga
}

\section{Resumo}

Interferências oclusais têm sido consideradas fatores predisponentes e/ou perpetuadores das disfunções temporomandibulares (DTMs). Dentro deste contexto, este estudo tem como objetivo avaliar hiperalgesia inflamatória decorrente da alteração oclusal na ATM de ratos através de análises comportamentais. Para este estudo foram utilizados ratos machos Wistar ( $\pm 150 \mathrm{~g}, \mathrm{n}=4$-6/grupo, protocolo aprovado pela Comissão de Ética no Uso de Animais \#4001-1 da FOP/UNICAMP) que foram anestesiados por via intramuscular e posicionados em um dispositivo para possibilitar a abertura bucal para a cimentação (cimento resinoso) de coroas metálicas fundidas de $0,4 \mathrm{~mm}$ ou $0,7 \mathrm{~mm}$ de espessura, recobrindo todas as faces do primeiro molar inferior direito com exceção da face distal, permitindo a adaptação da coroa ao dente. Após o período de 21 ou 28 dias da instalação das coroas, os animais foram submetidos a um teste comportamental e avaliados através da resposta nociceptiva induzida por formalina $0,5 \%$ (dose sublimiar) na região ATM. Os grupos de animais em que não foi realizada a instalação das coroas foram denominados "controle". Os resultados demonstraram que, nos animais em que houve instalação das coroas e, portanto, interferência oclusal, o comportamento nociceptivo induzido pela formalina $0,5 \%$ na ATM foi significativamente maior comparado ao dos grupos controles $(\mathrm{P}<0,05$ : ANOVA, Teste de Tukey), independente do período em que foram submetidos à interferência. No entanto, os animais com coroas de $0,7 \mathrm{~mm}$ apresentaram uma resposta nociceptiva maior quando comparada à dos animais com coroas de $0,4 \mathrm{~mm}(\mathrm{P}<0,05$ : ANOVA, Teste de Tukey). Esses resultados sugerem que alterações oclusais são fatores predisponentes da hiperalgesia inflamatória na ATM, e que a hiperalgesia desenvolvida nesta região é diretamente proporcional à altura da interferência oclusal.

Palavras-chave: Interferência oclusal, DTM, Inflamação.

\section{Introdução}

Interferências oclusais têm sido consideradas fatores predisponentes e/ou perpetuadores das DTMs.

Objetivo: avaliar hiperalgesia inflamatória decorrente da alteração oclusal na ATM de ratos através de análises comportamentais.

\section{Resultados e Discussão}

Ratos machos Wistar $( \pm 150 \mathrm{~g}, \mathrm{n}=4$-6/grupo, CEA \#4001-1) foram anestesiados para a cimentação de coroas metálicas fundidas de $0,4 \mathrm{~mm}$ ou $0,7 \mathrm{~mm}$ de espessura.

Figura 1. Mobilização do animal anestesiado para instalação das coroas.
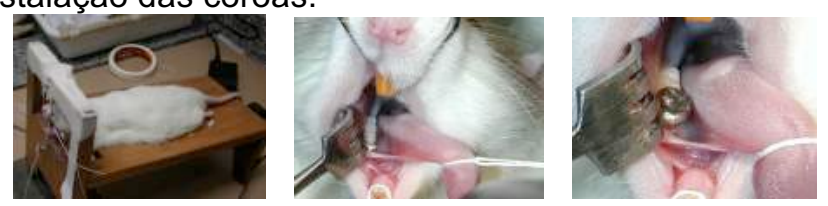

Após 21 ou 28 dias da instalação das coroas, os animais foram submetidos a um teste comportamental, avaliados através da resposta nociceptiva induzida por formalina $0,5 \%$ na ATM. Os grupos de animais em que não foi realizada a instalação das coroas foram denominados "controle".

Figura 2. Injeção na região da ATM e quantificação do comportamento nociceptivo.
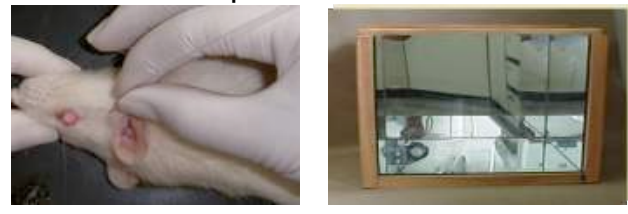

Resultados: nos animais com interferência oclusal o comportamento nociceptivo induzido pela formalina $0,5 \%$ na ATM foi significativamente maior comparado ao dos grupos controles, e os animais com coroas de $0,7 \mathrm{~mm}$ apresentaram uma resposta nociceptiva significativamente maior quando comparada à dos animais com coroas de $0,4 \mathrm{~mm}(\mathrm{P}<0,05$ : ANOVA, Teste de Tukey).

Figura 3. Quantificação do comportamento nociceptivo .

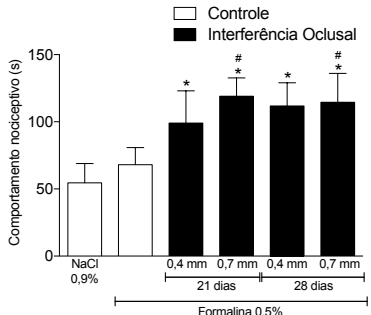

Fig. 3. Grupos com coroas apresentaram um comportamento nociceptivo induzido pela formalina $0,5 \%$ na ATM significativamente maior comparado ao dos grupos controles ( $P<0,05$ : ANOVA, Teste de Tukey, indicado pelo símbolo “*”); os animais com coroas de $0,7 \mathrm{~mm}$ apresentaram uma resposta nociceptiva significativamente maior quando comparada à dos animais com coroas de $0,4 \mathrm{~mm}(\mathrm{P}<0,05$ : ANOVA, Teste de Tukey, indicado pelo símbolo "\#”).

\section{Conclusões}

Alterações oclusais são fatores predisponentes da hiperalgesia inflamatória na ATM. A hiperalgesia desenvolvida nesta região é diretamente proporcional à altura da interferência oclusal.

\section{Agradecimentos}

Ao CNPq, (PIBIC), pela bolsa de IC concedida. 